\title{
Ephedrine delays rocuronium recovery
}

\author{
Federico Piccioni, MD - Giulia T. A. Tramontano, MD • \\ Sergio Lassola, MD • Emiliano Tognoli, MD • \\ Martin Langer, MD
}

Received: 19 December 2012/ Accepted: 14 January 2013/Published online: 24 January 2013

(C) Canadian Anesthesiologists' Society 2013

\section{To the Editor,}

Ephedrine is a sympathomimetic amine used to treat hypotension. ${ }^{1}$ The onset time of neuromuscular blocking agents (NMBA) is influenced by muscle blood flow and cardiac output, ${ }^{2}$ and ephedrine can reduce the onset time of NMBAs by increasing these variables. ${ }^{3}$ Moreover, ephedrine seems to increase acetylcholine release ${ }^{1}$ and is used to treat congenital myasthenic syndromes. ${ }^{4}$ We report an unexpected case of reparalysis following ephedrine administration. This report is written with the patient's signed consent.

A 63-yr-old male $(83 \mathrm{~kg}, 174 \mathrm{~cm})$ underwent anterior resection for rectal cancer. After anesthesia induction with propofol and remifentanil, muscle relaxation was achieved with rocuronium $50 \mathrm{mg}$. Anesthesia was maintained with desflurane and epidural $0.375 \%$ ropivacaine. Neuromuscular function was monitored by acceleromyography (AMG) at the adductor pollicis muscle using a train-of-four (TOF)-Watch ${ }^{\circledR}$ SX monitor interfaced with a computer using the TOF-Watch SX monitor software (Organon, Ireland, now Merck \& Co., USA). The acceleration transducer was placed with the hand adapter (Hand-Adapter ${ }^{\circledR}$; Organon, Ireland, now Merck \& Co., USA). Surgery lasted $152 \mathrm{~min}$, and rocuronium $10 \mathrm{mg}$ was administered throughout the procedure every time the second twitch $\left(\mathrm{T}_{2}\right)$ in the train-of-four reappeared; the total rocuronium dose

F. Piccioni, MD $(\bowtie) \cdot$ E. Tognoli, MD $\cdot$ M. Langer, MD Department of Anesthesia, Intensive Care and Palliative Care, Fondazione IRCCS Istituto Nazionale dei Tumori, Milan, Italy e-mail: federico.piccioni@istitutotumori.mi.it

G. T. A. Tramontano, MD - S. Lassola, MD - M. Langer, MD Department of Pathophysiology and Transplantation, University of Milan, Milan, Italy was $70 \mathrm{mg}$. At the end of surgery, a hypotensive episode occurred (mean arterial pressure $<50 \mathrm{mmHg}$ ); ephedrine $5 \mathrm{mg} i v$ was administered and blood pressure was restored rapidly. At the time of the ephedrine injection, which was $68 \mathrm{~min}$ following the previous rocuronium bolus, the first twitch $\left(\mathrm{T}_{1}\right)$ was $25 \%$ and the train-of-four ratio was (TOFR) $38 \%$. Two minutes later, the $\mathrm{T}_{1}$ had decreased to $19 \%$ and the TOFR had decreased to $0 \%$ (Figure). The fourth twitch reappeared four minutes after ephedrine administration, and almost nine minutes elapsed before the TOFR reached its pre-ephedrine administration value. Ten minutes later, the TOFR was $55 \%$ and, therefore, sugammadex (100 mg) was administered. Two minutes later, the patient's trachea was extubated and he was returned to the surgical ward one hour later.

In this case, ephedrine was administered when the patient was recovering spontaneously from neuromuscular blockade $\left(\mathrm{T}_{1}=25 \%\right.$ and TOFR $\left.=38 \%\right)$. After ephedrine administration, we expected the patient's blood pressure to increase without any neuromuscular effect. Instead, two minutes after ephedrine administration, $\mathrm{T}_{1}$ decreased to $19 \%$ and the TOFR was $0 \%$.

A strict AMG monitoring was performed throughout the entire operation to reduce NMBA accumulation in peripheral compartments. Nevertheless, we observed more intense blockade after ephedrine. The onset time of NMBAs is influenced by different hemodynamic factors, ${ }^{3}$ and since rocuronium is a drug with a fast onset of effect, the blood effect-site equilibration constant is correlated with cardiac output. ${ }^{2}$ Therefore, by increasing cardiac output and tissue perfusion, we assumed that ephedrine could have enhanced inter-compartmental clearance of rocuronium ${ }^{5}$ which flowed back into blood circulation to be redistributed to the neuromuscular junction. We did not observe a reversal effect driven by ephedrine-related 


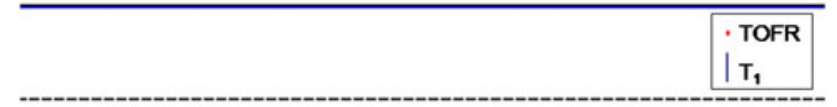

Ephedrine $5 \mathrm{mg}$

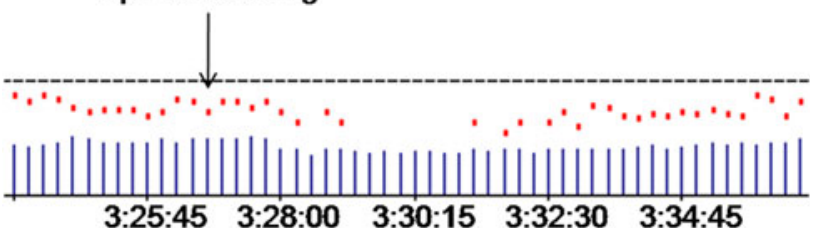

$3: 25: 45 \quad 3: 28: 00 \quad 3: 30: 15 \quad 3: 32: 30 \quad 3: 34: 45$

Figure The effect of ephedrine on rocuronium recovery. Neuromuscular monitoring with TOF-Watch ${ }^{\circledR}$ SX shows a gradual increase of first twitch $\left(\mathrm{T}_{1}\right.$ - vertical lines) and train-of-four ratio (TOFR -

values. After ephedrine administration (three hours, $26 \mathrm{~min}$ and 45 sec after induction) a decrease of $\mathrm{T}_{1}$ and TOFR values can be observed. A few minutes later the $T_{1}$ starts to increase and the TOFR reappears (three hours, $31 \mathrm{~min}$ and $15 \mathrm{sec}$ after induction)

acetylcholine release, probably because of the low dose of ephedrine administered. We exclude the possibility that residual rocuronium from a previous administration at the injection site could have been flushed into the circulation by ephedrine because fluids were delivered by a volumetric pump. Strangely, we never obtained TOFR values between 0 and $30 \%$, suggesting that our monitoring was not optimal. Nevertheless, we performed six train-of-four stimulations prior to calibration, and no changes in the patient's arm position occurred during the procedure.
During general anesthesia with NMBA, monitoring of neuromuscular function is highly recommended, and anesthesiologists should keep in mind that ephedrine can delay recovery from rocuronium. This could be an important issue, especially in order to prevent residual neuromuscular blockade. A prospective observational study could be designed to test our hypothesis.

Federico Piccioni received a consulting fee for participating in an expert meeting forum organized by MSD Italia Srl (in 2012). Other authors have no conflicts of interest. No external funding declared.

\section{References}

1. Malta E, McPherson GA, Raper C. Comparison of pre-junctional alpha-adrenoreceptors at the neuromuscular junction with vascular post-junctional alpha-receptors in cat skeletal muscle. $\mathrm{Br} \mathrm{J}$ Pharmacol 1979; 65: 249-56.

2. Kuipers JA, Boer F, Olofsen E, Bovill JG, Burm AG. Recirculatory pharmacokinetics and pharmacodynamics of rocuronium in patients: the influence of cardiac output. Anesthesiology 2001; 94: 47-55.

3. Donati F. Onset of action of relaxants. Can J Anaesth 1988; 35 : S52-8.

4. Schara $U$, Lochmuller $H$. Therapeutic strategies in congenital myasthenic syndromes. Neurotherapeutics 2008; 5: 542-7.

5. Henthorn TK, Krejcie TC, Avram MJ. The relationship between alfentanil distribution kinetics and cardiac output. Clin Pharmacol Ther 1992; 52: 190-6. 